\title{
P 010 PALLIATIVE AND END OF LIFE CARE IN PRISONS IN GREAT BRITAIN AND NORTHERN IRELAND - EXPERIENCES OF PHYSICIANS WORKING IN SPECIALIST PALLIATIVE CARE SERVICES
}

Andrew Fletcher, ${ }^{1}$ Sheila Payne, ${ }^{2}$ David Waterman, ${ }^{3}$ Mary Turner ${ }^{2} .{ }^{1}$ St Catherine's Hospice, Preston, UK; ${ }^{2}$ Lancaster University, Lancaster, UK; ${ }^{3}$ Stockport NHS Foundation Trust, Stockport, UK

10.1136/bmjspcare-2014-000654.51

Background The End of Life Care Strategy (2008) states: 'high quality services should be available in all locations, including prisons,' and recommends collaborative working across the prisons, coronial, healthcare and specialist palliative care services.

Aims and Methods The aim of the study was to explore experiences of physicians working in specialist palliative care, in caring for prisoners and their views about facilitators and barriers, to providing high quality care. An online questionnaire was distributed to members of the Association of Palliative Medicine of Great Britain and Ireland.

Results Two hundred and thirty-six completed questionnaires (23.3\% response rate). One hundred and thirty-seven $(58.1 \%)$ respondents had experience of caring for prisoners. The most common reasons for review included pain control (23.6\%), symptom control (27.6\%) and end of life care (20.5\%). The interface between services in prisons was identified as complex by 173 (73.3\%) of respondents-impacting on delivery of care, requiring a comprehensive interface between staff inside and specialist palliative care services outside the prison. Ninety-six (39.4\%) respondents were willing to be involved in the delivery of an education programme and $128(54.2 \%)$ were keen to learn about prison structures and healthcare. Ninety respondents were unsure if end of life care tools could be implemented within prisons.

Conclusions There are consistent perceptions regarding factors that enhance palliative and end of life care in prisons. These include the need to develop working relationships, and enhance communication, within the prison as well as between the prison and outside agencies. The development of education and research, management of public perceptions and the review of policies, procedures and legal issues were highlighted. There is willingness by physicians to engage with the prison service to develop and support palliative and end of life care. Strategic development at local and national level is important due to the unique characteristics of each prison. 